07

\title{
Тритиевые источники электропитания на основе гетероструктур AIGaAs/GaAs
}

\author{
( В.П. Хвостиков, В.С. Калиновский, С.В. Сорокина, О.А. Хвостикова, В.М. Андреев \\ Физико-технический институт им. А.Ф. Иоффре РАН, Санкт-Петербург, Россия \\ E-mail: vlkhv@scell.ioffe.ru
}

Поступило в Редакцию 20 июня 2019г.

В окончательной редакции 18 июля 2019г.

Принято к публикации 27 августа 2019г.

\begin{abstract}
Приведены результаты разработки радиоизотопного источника электропитания на основе полупроводникового $\left(\mathrm{Al}_{x} \mathrm{Ga}_{1-x} \mathrm{As} / \mathrm{GaAs}\right)$ преобразователя энергии $\beta$-излучения и трития в качестве источника излучения. Проведено сравнение эффективности преобразователя при использовании в качестве источника радиоизотопного излучения насыщенного тритием титанового диска, тритиевой лампы зеленого люминесцентного свечения и газообразного трития. При использовании преобразователя на основе гетероструктуры $\mathrm{Al}_{0.35} \mathrm{Ga}_{0.65} \mathrm{As} / \mathrm{GaAs}$ в капсуле с тритием получен КПД $\eta=5.9 \%$ при максимальной выходной удельной электрической мощности $0.56 \mu \mathrm{W} / \mathrm{cm}^{2}$. За счет длительного ресурса работы такие автономные и компактные источники электропитания могут использоваться в космической и подводной технике, в имплантатахкардиостимуляторах, биологических датчиках, портативном мобильном оборудовании высокой надежности.
\end{abstract}

Ключевые слова: радиоизотопный источник питания, тритий, $\beta$-излучение, $\mathrm{AlGaAs} / \mathrm{GaAs}$.

DOI: 10.21883/PJTF.2019.23.48716.17941n

В отличие от традиционных фотоэлементов, облучаемых фотонами, в радиоизотопных источниках электропитания (РИЭП) используется энергия $\beta$-распада (прямое преобразование энергии $\beta$-частиц) $[1-3]$ или радиолюминесцентное излучение (двухступенчатое преобразование активированного свечения люминофоров) $[4,5]$. Основными требованиями, предъявляемыми к РИЭП, являются большой срок эксплуатации (до 10-20 лет), высокая эффективность и выходная удельная мощность при малой энергии ионизирующего излучения для предупреждения деградации бета-вольтаического преобразователя (БВП), доступная стоимость, отсутствие загрязнения окружающей среды. За счет длительного ресурса работы РИЭП находят практическое применение при использовании в агрессивных средах, в удаленных или труднодоступных местах (в космической, морской и подводной технике, на Крайнем Севере, в имплантатах-кардиостимуляторах, протезных устройствах и биологических датчиках). Такие источники питания не нагреваются при эксплуатации, а после снижения активности изотопа не содержат токсичных веществ.

Характеристики РИЭП зависят от свойств изотопа, выбора конструкции и полупроводникового материала БВП. Ранее сообщалось об использовании ${ }^{90} \mathrm{Sr}-{ }^{90} \mathrm{Y}[6]$, однако в настоящее время большее распространение получают $\beta$-батареи на основе ${ }^{147} \mathrm{Pm}[7],{ }^{63} \mathrm{Ni}$ или трития $[3,7]$. Сравнение активности, безопасности, доступности и стоимости изотопов показывает, что тритий - один из лучших кандидатов в качестве источника излучения. Он относится к нестабильным изотопам с достаточно большим (12.3 года) периодом полураспада, в процессе которого превращается в гелий и испускает электроны с максимальной энергией $18.6 \mathrm{keV}$. Излучение низких энергий не приводит к заметной генерации дефектов в полупроводнике и деградации БВП. Максимальный пробег электронов на воздухе при распаде трития составляет $4.2 \mathrm{~mm}$, поэтому при внешнем облучении тритий не представляет серьезной угрозы и не требует дополнительной биологической защиты (в отличие от ${ }^{90} \mathrm{Sr}$ или ${ }^{147} \mathrm{Pm}$ ). Тритий характеризуется относительно низкой стоимостью и доступностью в виде тритий-титановой фольги и радиолюминесцентных тритиевых ламп (герметично запаянных и заполненных газообразным тритием стеклянных капсул, внутренняя поверхность которых покрыта люминофором).

В бета-вольтаических РИЭП используются преимущественно преобразователи на основе кремния $[8,9]$ и полупроводников $\mathrm{A}^{3} \mathrm{~B}^{5}[3,10]$, в которых существует возможность изменения ширины запрещенной зоны. Для БВП на основе кремния эффективность $(\eta)$ теоретически может достигать $\sim 15 \%$, в $\mathrm{AlGaAs} / \mathrm{GaAs} \sim 22 \%$, в $\mathrm{GaP} \sim 24 \%[1]$.

В настоящей работе представлены результаты создания и исследования РИЭП на основе эпитаксиальных гетероструктур $\mathrm{AlGaAs} / \mathrm{GaAs}$ с использованием тритиевых эмиттеров различного типа. БВП с ультратонкими фронтальными слоями были выращены методом эпитаксии из жидкой фазы при пониженной температуре кристаллизации $\left(400-500^{\circ} \mathrm{C}\right)$. Приборная структура включала буферный слой $n$-GaAs, $p$-n-переход в $\mathrm{Al}_{x} \mathrm{Ga}_{1-x} \mathrm{As} / \mathrm{GaAs}(x=0.1-0.35)$, ультратонкий широкозонный $p-\mathrm{Al}_{0.85} \mathrm{Ga}_{0.15} \mathrm{As}$ и контактный слой $p^{+}$-GaAs, удаляемый в местах, свободных от фронтальной металлизации. 


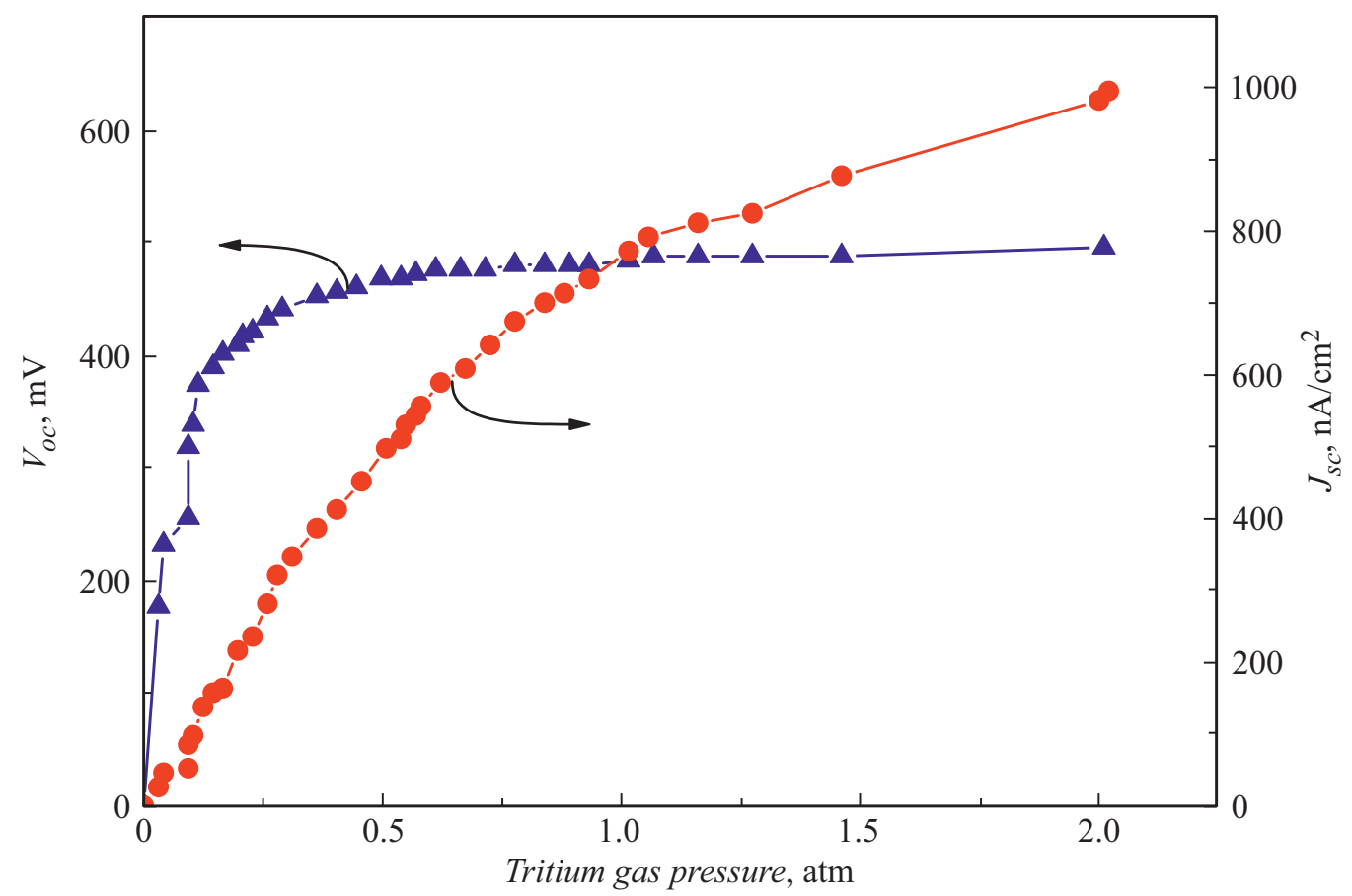

Рис. 1. Напряжение холостого хода $\left(V_{o c}\right)$ и ток короткого замыкания $\left(J_{s c}\right)$ БВП на основе гетероструктур $\mathrm{Al}_{0.1} \mathrm{Ga}_{0.9} \mathrm{As}$ $\left(S=0.3 \mathrm{~cm}^{2}\right)$ в зависимости от давления газообразного трития.

Таблица 1. Параметры помещенных в капсулу, заполненную газообразным тритием, БВП с $p-n$-переходом в $\mathrm{Al}_{0.15} \mathrm{Ga}_{0.85} \mathrm{As}_{\mathrm{s}}$ $\mathrm{Al}_{0.35} \mathrm{Ga}_{0.65} \mathrm{As}$

\begin{tabular}{c|c|c}
\hline \multirow{2}{*}{ Параметр } & \multicolumn{2}{|c}{ Значение } \\
\cline { 2 - 3 } & Активная область $\mathrm{Al}_{0.15} \mathrm{Ga}_{0.85} \mathrm{As}$ & Активная область $\mathrm{Al}_{0.35} \mathrm{Ga}_{0.65} \mathrm{As}$ \\
\hline Плотность фототока, $\mu \mathrm{A} / \mathrm{cm}^{2}$ & 1.0 & 0.76 \\
Напряжение холостого хода $V_{o c}, \mathrm{~V}$ & 0.65 & 0.9 \\
Коэффициент заполнения ВАХ $F F, \%$ & 78 & 79 \\
$\eta, \%$ & 5.4 & 5.9
\end{tabular}

Таблица 2. Параметры БВП при облучении различными тритиевыми источниками излучения

\begin{tabular}{|c|c|c|c|}
\hline Источник $\beta$-излучения & $\begin{array}{c}\text { Плотность фототока, } \\
\mathrm{nA} / \mathrm{cm}^{2}\end{array}$ & $\begin{array}{c}\text { Напряжение } \\
\text { холостого хода, V }\end{array}$ & $\begin{array}{c}\text { Плотность } \\
\text { выходной } \\
\text { мощности, } \mathrm{nW} / \mathrm{cm}^{2}\end{array}$ \\
\hline $\begin{array}{l}\text { Тритий-титановый } \\
\text { твердотельный } \\
\text { эмиттер } \\
\text { Капсулированный } \\
\text { газообразный тритий } \\
\text { Тритиевая лампа } \\
\text { зеленого }(550 \mathrm{~nm}) \\
\text { свечения }\end{array}$ & $\begin{array}{r}58 \\
760 \\
180\end{array}$ & $\begin{array}{l}0.62 \\
0.91 \\
0.79\end{array}$ & $\begin{array}{r}27 \\
560 \\
100\end{array}$ \\
\hline
\end{tabular}




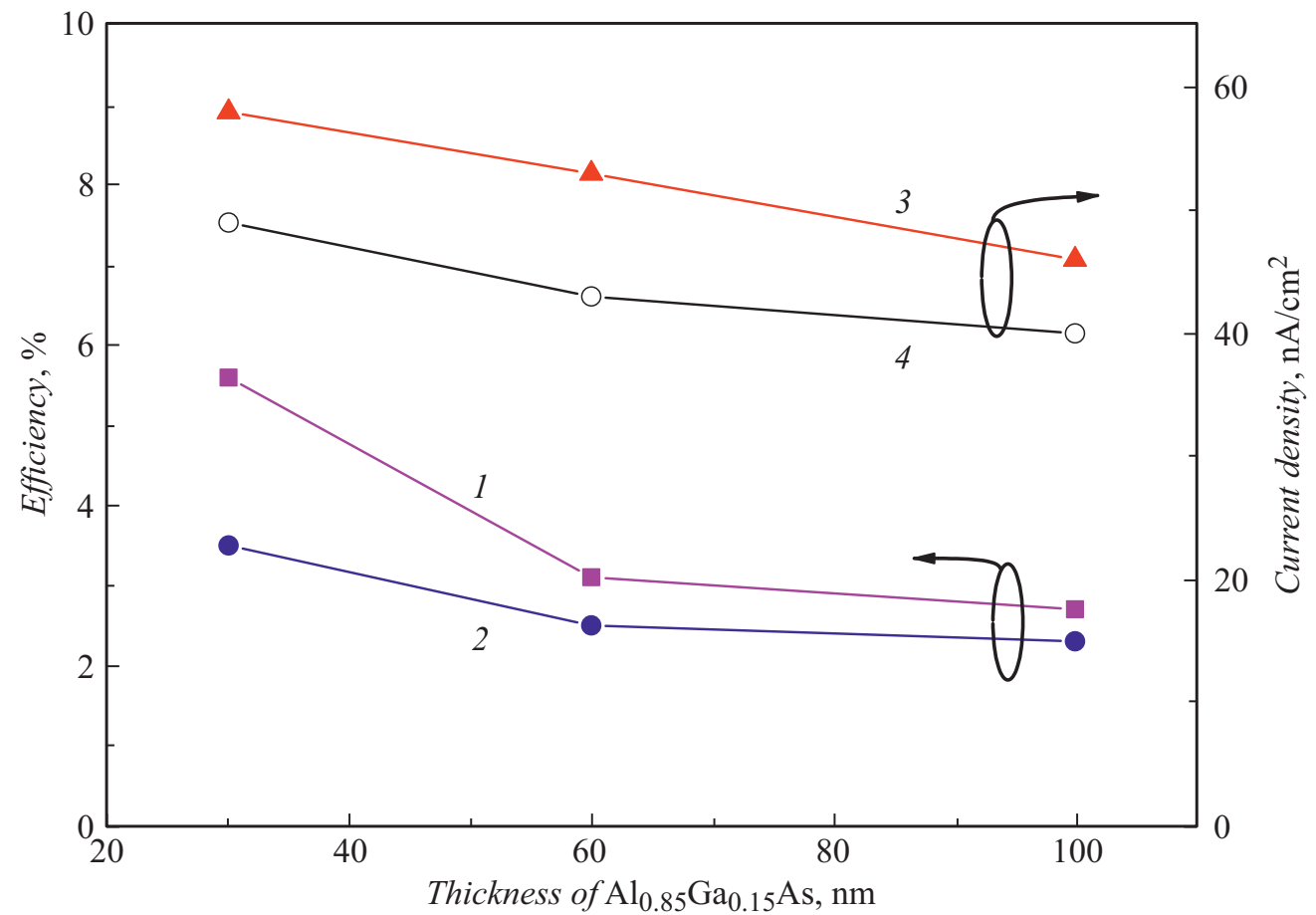

Рис. 2. Зависимость КПД $(1,2)$ и плотности генерированного тока $(3,4)$ от толщины широкозонного слоя $\mathrm{Al}_{0.85} \mathrm{Ga}_{0.15} \mathrm{As}$ в БВП в случае тритий-титанового источника с мощностью $0.48 \mu \mathrm{W} / \mathrm{cm}^{2} .1,3$ - структуры с $p$-n-переходом в $\mathrm{Al}_{0.25} \mathrm{Ga}_{0.75} \mathrm{As}_{\text {без }}$ защитного покрытия, 2, 4 - с защитной пленкой $\mathrm{ZnS}(50 \mathrm{~nm})$.

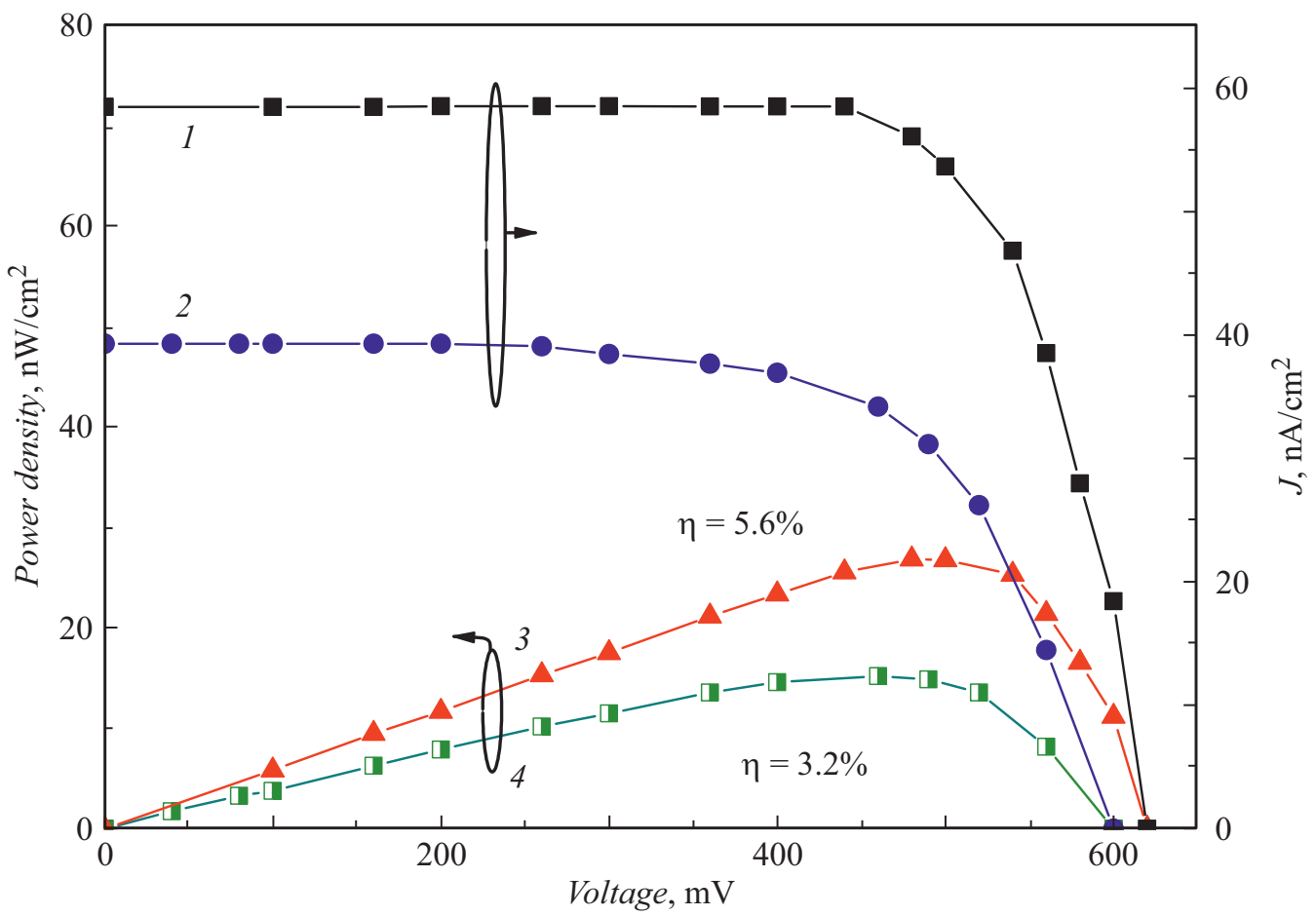

Рис. 3. Вольт-амперные характеристики $(\mathrm{BAX})(1,2)$ и зависимости мощность-напряжение $(3,4)$ в БВП на основе $\mathrm{Al}_{0.25} \mathrm{Ga}_{0.75} \mathrm{As}$ без защитного покрытия $(1,3)$ и с пленкой $\mathrm{ZnS}(2,4)$ в случае тритий-титанового источника с мощностью излучения $0.48 \mu \mathrm{W} / \mathrm{cm}^{2}$. 
Исследовались три типа источников $\beta$-излучения: - тритий-титановый диск с диаметром $1-1.5 \mathrm{~cm}$;

- $\beta$-люминесцентные лампы зеленого свечения;

- капсулированный газообразный тритий.

В последнем случае БВП с активной площадью $S=0.3-1.0 \mathrm{~cm}^{2}$ помещался внутрь объема, заполненного тритием (в капсулу) до давления 1-2 atm. Плотность генерированного фототока при этом достигала $\sim 10^{-6} \mathrm{~A} / \mathrm{cm}^{2}$ (рис. 1).

В табл. 1 представлены выходные параметры помещенных в капсулу бета-вольтаических преобразователей с различающейся по содержанию алюминия активной областью. На лучших образцах с $p$-n-переходом в $\mathrm{Al}_{0.35} \mathrm{Ga}_{0.65} \mathrm{As}$ достигнуты значения КПД $\eta=5.9 \%$ и выходная удельная мощность $0.56 \mu \mathrm{W} / \mathrm{cm}^{2}$.

Твердотельные тритий-титановые радиоактивные источники $\beta$-излучения генерируют значительно меньшую выходную электрическую мощность, чем при использовании газообразного трития (таблица 2). Характеристики БВП в случае тритий-титанового эмиттера показаны на рис. 2,3. Как следует из представленных зависимостей, при плотности мощности $\beta$-излучения $0.48 \mu \mathrm{W} / \mathrm{cm}^{2}$ с уменьшением толщины широкозонного слоя $\mathrm{Al}_{0.85} \mathrm{Ga}_{0.15} \mathrm{As}$ от $d \sim 100$ до $30 \mathrm{~nm}$ генерированный фототок возрастал в 1.5 раза. Нанесение на поверхность гетероструктуры защитной пленки $\mathrm{ZnS}$ (толщиной $\sim 50 \mathrm{~nm})$ приводило к уменьшению плотности генерируемого тока на $15-20 \mathrm{nA} / \mathrm{cm}^{2}$ за счет ,бесполезного“ поглощения в слое $\mathrm{ZnS}$ (рис. 3, кривые 3,4). В БВП с $p$-n-переходом в $\mathrm{Al}_{0.25} \mathrm{Ga}_{0.75} \mathrm{As}$ в случае тритийтитанового источника излучения получены плотность выходной электрической мощности $15-27 \mathrm{nW} / \mathrm{cm}^{2}$ и КПД $\eta=5.6 \%$ (рис. 3 ).

Двухэтапное преобразование свечения активированных тритием люминофоров (табл. 2) может обеспечить достаточно высокую оптическую эффективность благодаря точной подстройке ширины запрещенной зоны фотоэлемента $\mathrm{Al}_{x} \mathrm{Ga}_{1-x} \mathrm{As} / \mathrm{GaAs}$ под длину волны источника, однако требует специальных мер по уменьшению потерь на накачку люминофора, а также минимизации самопоглощения в нем и рассеяния выходящего излучения, что в итоге снижает суммарный КПД.

Таким образом, проведенные исследования показывают, что наиболее перспективным типом тритиевых РИЭП, обеспечивающим максимальную выходную электрическую мощность и высокий суммарный КПД, являются капсулированные с газообразным тритием гетероструктурные элементы $\mathrm{Al}_{x} \mathrm{Ga}_{1-x} \mathrm{As} / \mathrm{GaAs}$ для прямого преобразования энергии $\beta$-частиц.

\section{Конфликт интересов}

Авторы заявляют, что у них нет конфликта интересов.

\section{Список литературы}

[1] Olsen L.C. Review of betavoltaic energy conversion // Proc. 12th Space Photovoltaic Research and Technology Conf. Cleveland, 1992. P. 256-267.

[2] Olsen L.C., Cabauy P., Elkind B.J. // Phys. Today. 2012. V. 65. N 12. P. 35-38.

[3] Андреев В.М., Калиновский В.С., Ларионов В.Р., Стругова Е.О., Румянцев В.Д. // ФТП. 1994. Т. 28. В. 2. С. 338-342.

[4] Kherani N.P., Shmayada W.T. // Z. Phys. Chem. 1994. V. 183. N 5. P. 453-463.

[5] Хвостиков В.П., Калиновский В.С., Сорокина С.В., Швари, М.З., Потапович Н.С., Хвостикова О.А., Власов А.С., Андреев В.М. // ФТП. 2018. Т. 52. В. 13. С. $1647-$ 1650. DOI: $10.21883 /$ FTP.2018.13.46881.8942

[6] Rappaport P. // Phys. Rev. 1954. V. 93. P. 246-247.

[7] Yakubova G.N. Nuclear batteries with tritium and promethium-147 radioactive sources. $\mathrm{PhD}$ thesis. University of Illinois at Urbana-Champaign, 2010. $162 \mathrm{p}$.

[8] Deus S. Tritium-powered betavoltaic cells based on amorphous silicon // Conf. Record of the IEEE Photovoltaic Specialists Conf. IEEE, 2000. P. 1246-1249. DOI: 10.1109/PVSC.2000.916115

[9] Kosteski T., Kherani N.P., Gaspari F., Zukotynski S., Shmayda W.T. // J. Vac. Sci. Technol. A. 1998. V. 16. P. 893 896. DOI: $10.1116 / 1.581031$

[10] Войтович В., Гордеев А., Думаневич А. // Современная электроника. 2015. № 6. С. 10-17. 